\title{
The Advantage of Asymmetrical Handedness in Cooperation with Heartbeat: A Hypothesis from the Chinese Member of Satellite Group
}

\author{
Zi-Jian Cai \\ CaiFortune Consulting, Suzhou, China \\ Email: hrsh8@126.com
}

How to cite this paper: Cai, Z.-J. (2016) The Advantage of Asymmetrical Handedness in Cooperation with Heartbeat: A Hypothesis from the Chinese Member of Satellite Group. Open Access Library Journal, 3: e3253.

http://dx.doi.org/10.4236/oalib.1103253

Received: November 22, 2016

Accepted: December 5, 2016

Published: December 8, 2016

Copyright $\odot 2016$ by authors and Open Access Library Inc.

This work is licensed under the Creative

Commons Attribution International

License (CC BY 4.0).

http://creativecommons.org/licenses/by/4.0/

(c) (i) Open Access

\section{Abstract}

Recently, it was published the book "Electromagnetic Unification of Four Forces" (ISBN 978-3-659-76798-2), compiling the progressions in physics manifested in television, made by the world people while led notably by the author and the members in the world satellite networks from India, Zhejiang and USA. Besides these significant achievements, it has also been made many activities and achievements on neural sciences. In this article, it is relayed, via the author as the main holder of them, a new hypothesis raised by a Chinese Member of satellite group, which has also been manifested in television already, but required to be transformed into written form for scientists to read and cite. It was newly suggested that the advantage of asymmetrical handedness might correlate to its long-term cooperation with heartbeat during muscular contraction and limb movement. It is in further supported herein by the evidence in followings: 1) the developmental canalization to heart asymmetry in vertebrate evolution; 2) the decreased survival fitness of left-handedness from coronary artery disease; 3) the higher frequencies of heart irregularities in individuals of left handedness than right handedness; 4) the laterality of brain in control of heart rate variability. It is additionally speculated that the asymmetry of heart in fish without limb might likewise correlate to the long-term compatibility between the heartbeat and contralateral muscular contraction. In this regard, it is concluded that this hypothesis from the Chinese Member of satellite group may become an important solution toward understanding the advantage of both bodily and brain asymmetry.

\section{Subject Areas}

Developmental Biology, Genetics, Neuroscience

\section{Keywords}

Laterality, Brain, Heart, Handedness, Bodily Movement, Compatibility 


\section{Introduction}

Cerebral asymmetry has been the subject attracting the attention of scientists for many decades. The advantage of cerebral asymmetry has been the hot theme of theorists from year to year. There have been raised many theories about the advantage of cerebral asymmetry, briefly as followings: 1 ) cognitive benefits, especially spatial ability in adults and verbal ability in children [1];2) semantic processing against interference [2], such as stuttering [3] [4] [5];3) alignment at population level by behavioral coordination or learning [6] [7]; 4) generation of language from manual gesture [8]; 5) genetic shifting to right handedness [9].

Even though diverse, none of them have considered how the cerebral asymmetry can match to the bodily asymmetry altogether. In this article, it is introduced a new hypothesis from a Chinese member of satellite group, considering together the advantage of both brain and bodily asymmetry.

\section{The Hypothesis}

Recently, it was published the book "Electromagnetic Unification of Four Forces" (ISBN 978-3-659-76798-2), which compiled the progressions in physics made by the world people and manifested in television, while led notably by the author and the Members in the world satellite networks from India, Zhejiang and USA. Besides these significant achievements, there have also been many activities and achievements on neural sciences in television.

In this article, via the author as the main holder of satellite group, it is introduced a new hypothesis on the advantage of both brain and bodily asymmetry, which was raised by a male Chinese Member of satellite group. Because it has already been relayed to and manifested in television, known to the Chinese people in various public situations such as news, live art/sport performances and so on, to publish his hypothesis it is not necessary to consider the name of the Chinese Member of satellite group, nor his agreement. This article merely transforms this achievement recorded in television into a written paper for the convenience of scientists to read and cite.

The new hypothesis was initially postulated by a male Chinese Member of satellite group on February 5, 2009. At that moment, while I was considering that the asymmetrical handedness might result from the rotation of earth, this Chinese Member of satellite group said to me via the thermoacoustic satellite sound, and newly suggested that the advantage of asymmetrical handedness might correlate to its long-term cooperation with heartbeat during muscular contraction and arm movement. He pointed out that the strong muscular contraction and big arm movement on the right side in most right handedness would hamper the heartbeat and blood flow if the heart had been located also in the same right side, therefore naturally the right handedness matched well with the left heartbeat, and in long term the right handedness would acquire advantage.

\section{Supporting Evidence}

There are many lines of evidence in support of this new hypothesis from the male Chi- 
nese Member of satellite group. They are listed as followings:

1) Both bodily and brain asymmetry have been one of the focused themes of developmental biology on vertebrates for decades of years [10] [11]. Most notably, it has been demonstrated that the heart asymmetry generated in development is canalized to such conserved symmetry-breaking processes as the activity of the nodal cilia in vertebrates [10] [12], with various earlier biochemical events converging to it [10] [13]. Besides, it is also well known that the brain structural asymmetries are present in the epithalamus of several species of fishes and amphibians [11]; and has been shown the behavioral asymmetries in the direction of turning and eye use during escape behavior in poeciliid fish, the pectoral stridulation sounds in catfish, the control of vocalization in frogs; the courtship behavior in newts; and the aggressive responses in lizards [11]. At the biochemical level, lateralization has been observed in both humans and rats on the biochemical markers including those on nitric oxide synthetic pathway [14] [15]. These developmental, behavioral, and biochemical studies clearly demonstrate that the heart and brain asymmetry are conserved during vertebrate evolution, even though with the cause of such conservation left unknown.

2) If the hypothesis is correct, then it would be expected that the left handedness should manifest as somewhat less adaptive than the right handedness. This is really the situation. It has been shown that the non-right handedness is higher in risk for sudden death associated with coronary artery disease [16]. Besides, it has been demonstrated that the left-handers are drastically underrepresented in the oldest age groups due to the reduced longevity of them [17]. Obviously, the right handedness is somewhat safer than others due to its advantage in cooperation with left heart.

3) It has been shown that the heart rate variability differed significantly between individuals of right and left handedness [18]. The left-handers manifested higher frequencies of heart irregularities [18]. Obviously, due to the compatibility of left heartbeat with right handedness in muscular contraction and arm movement, the righthanders acquire the advantage as regularity of heart rate than the left-handers.

4) The heart rate variability is controlled asymmetrically [19] [20], more by the right brain hemisphere and contralateral to the hemisphere controlling the right hand [19]. Obviously, the lateralization in neural physiology matches to the compatibility between left heartbeat and right arm-movement.

In all, many lines of evidence support this new hypothesis from the Chinese Member of satellite group that the advantage of asymmetrical handedness correlates to its longterm cooperation with heartbeat during muscular contraction and arm movement, including the conservation of heart and brain asymmetry in development in vertebrates, the higher risk for non-right handedness in sudden death from coronary artery disease, the higher frequencies of heart irregularities in left-handers than right-handers, and the direct lateralization in neural regulation of heart rate variability.

\section{Discussions}

Even though many theories have been postulated to explain the advantage of cerebral 
asymmetry [1] [2] [6] [7] [8] [9], only this new hypothesis raised by the Chinese Member of satellite group correlates the hemispheric or behavioral laterality to the developmental bodily laterality. Besides, as demonstrated above, this hypothesis is very well supported with evidence in various aspects. In this regard, this hypothesis may become an important solution toward understanding the advantage of both brain and bodily asymmetry.

It is necessary to point out that, in fishes, there is no limb while they still manifest heart and brain asymmetry [10] [11] [12]. In some fishes, the structural asymmetries are present in the epithalamus of brain [11], while the behavioral asymmetries are present in the escape behavior and the pectoral stridulation sounds [11]. These exceptions can be explained in the similar way, just correlating the heartbeat to the contralateral contractile behavior of fish. It is easy to see that it would likewise be advantageous for the fish with asymmetrical heartbeat to be compatible with the contralateral muscular contraction in long term, even though not as salient as those vertebrates with limbs.

\section{Brief Perspectives}

Correlating the benefits of brain and bodily asymmetry into one behavioral advantage on compatibility of them is prospective in both science and application.

On the one hand, this new hypothesis may become an important solution toward understanding the advantage of both brain and bodily asymmetry, and can elicit new impetus of clinical and experimental investigations in the related fields.

On the other hand, this new hypothesis can help improve the relevant clinical practices, especially those dealing with the heart diseases in left handedness, the effects on heart health from unilateral/bilateral epilepsy, stroke or surgery, and so on.

\section{Conclusion}

In conclusion, in this article, it is introduced a new hypothesis raised by a male Chinese member of satellite group. The new hypothesis suggested that the advantage of asymmetrical handedness might correlate to its long-term compatibility with heartbeat during muscular contraction and arm movement. In this article, it is also supported with many lines of evidence for this new hypothesis, as in the followings: 1) the conservation of heart and brain asymmetry in development in vertebrates; 2) the higher risk for non-right handedness in sudden death from coronary artery disease; 3 ) the higher frequencies of heart irregularities in left-handers than right-handers; 4) the direct laterality in neural regulation of heart rate variability. It is attempted to transform this achievement recorded in television into a written paper for the convenience of scientists to read and cite.

\section{Acknowledgements}

It is herein acknowledged that MingXun Cai paid the Open Access publication fee of this paper. 


\section{Conflict of Interest}

The author declares no conflict of interest nor financial support for this work.

\section{References}

[1] Somers, M., Shields, L.S., Boks, M.P., Kahn, R.S. and Sommer, I.E. (2015) Cognitive Benefits of Right-Handedness: A Meta-Analysis. Neuroscience \& Biobehavioral Reviews, 51, 4863. https://doi.org/10.1016/j.neubiorev.2015.01.003

[2] Belanger, H.G. and Cimino, C.R. (2002) The Lateralized Stroop: A Meta-Analysis and Its Implications for Models of Semantic Processing. Brain and Language, 83, 384-402. https://doi.org/10.1016/S0093-934X(02)00508-4

[3] Cai, Z.J. (2015) Semantic Memory Association, Procedural Grammar Syntax and Episodic Modality Coordination as Three Interactive Neural Processes Organizing Language: A Model. Open Access Library Journal, 2, e1718. https://doi.org/10.4236/oalib.1101718

[4] Preibisch, C., Neumann, K., Raab, P., Euler, H.A., von Gudenberg, A.W., Lanfermann, H. and Giraud, A.L. (2003) Evidence for Compensation for Stuttering by the Right Frontal Operculum. NeuroImage, 20, 1356-1364. https://doi.org/10.1016/S1053-8119(03)00376-8

[5] Etchell, A.C., Johnson, B.W. and Sowman, P.F. (2014) Behavioral and Multimodal Neuroimaging Evidence for a Deficit in Brain Timing Networks in Stuttering: A Hypothesis and Theory. Frontiers in Human Neuroscience, 8, 467. https://doi.org/10.3389/fnhum.2014.00467

[6] Vallortigara, G. and Rogers, L.J. (2005) Survival with an Asymmetrical Brain: Advantages and Disadvantages of Cerebral Lateralization. Behavioral and Brain Sciences, 28, 575-589. https://doi.org/10.1017/S0140525X05000105

[7] Vallortigara, G. (2006) The Evolutionary Psychology of Left and Right: Costs and Benefits of Lateralization. Developmental Psychobiology, 48, 418-427. https://doi.org/10.1002/dev.20166

[8] Corballis, M.C. (2012) Lateralization of the Human Brain. Progress in Brain Research, 195, 103-121. https://doi.org/10.1016/B978-0-444-53860-4.00006-4

[9] Annett, M. (1996) In Defence of the Right Shift Theory. Perceptual \& Motor Skills, 82, 115-137. https://doi.org/10.2466/pms.1996.82.1.115

[10] López-Gracia, M.L. and Ros, M.A. (2007) Left-Right Asymmetry in Vertebrate Development. Advances in Anatomy, Embryology and Cell Biology, 188, 1-121.

[11] Bisazza, A., Rogers, L.J. and Vallortigara, G. (1998) The Origins of Cerebral Asymmetry: A Review of Evidence of Behavioural and Brain Lateralization in Fishes, Reptiles and Amphibians. Neuroscience \& Biobehavioral Reviews, 22, 411-426. https://doi.org/10.1016/S0149-7634(97)00050-X

[12] Spéder, P., Petzoldt, A., Suzanne, M. and Noselli, S. (2007) Strategies to Establish Left/Right Asymmetry in Vertebrates and Invertebrates. Current Opinion in Genetics \& Development, 17, 351-358. https://doi.org/10.1016/j.gde.2007.05.008

[13] Vandenberg, L.N. and Levin, M. (2013) A Unified Model for Left-Right Asymmetry? Comparison and Synthesis of Molecular Models of Embryonic Laterality. Developmental Biolo$g y, 379,1-15$. https://doi.org/10.1016/j.ydbio.2013.03.021

[14] Kristofiková, Z., et al. (2008) Lateralization of Hippocampal Nitric Oxide Mediator System in People with Alzheimer Disease, Multi-Infarct Dementia and Schizophrenia. Neurochemistry International, 53, 118-125. https://doi.org/10.1016/j.neuint.2008.06.009

[15] Kristofiková, Z., Rícný, J., Ort, M. and Rípová, D. (2010) Aging and Lateralization of the 
Rat Brain on a Biochemical Level. Neurochemical Research, 35, 1138-1146.

https://doi.org/10.1007/s11064-010-0165-8

[16] Lane, R.D., et al. (1994) Effects of Non-Right-Handedness on Risk for Sudden Death Associated with Coronary Artery Disease. The American Journal of Cardiology, 74, 743-747. https://doi.org/10.1016/0002-9149(94)90426-X

[17] Coren, S. and Halpern, D.F. (1991) Left-Handedness: A Marker for Decreased Survival Fitness. Psychological Bulletin, 109, 90-106. https://doi.org/10.1037/0033-2909.109.1.90

[18] Yüksel, R., Arslan, M. and Dane, S. (2014) Heart Rate Variability Differs between Rightand Left-Handed Individuals. Perceptual \& Motor Skills, 118, 890-896. https://doi.org/10.2466/19.10.PMS.118k24w5

[19] Panchani, J., et al. (2011) Asymmetric Hemispheric Representation of Periictal Heart Rate Modulation Is Individually Lateralised. Epileptic Disorders, 13, 172-176.

[20] Kuoppa, P., Niskanen, E., Karjalainen, P. and Tarvainen, M.P. (2012) Cerebral Cortex and Sub-Cortex Lateralization in Cardiovascular Regulation: Correlations of BOLD fMRI and Heart Rate Variability. 2012 International Conference of the IEEE Engineering in Medicine \& Biology Society, San Diego, 28 August-1 September 2012, 3412-3415.

https://doi.org/10.1109/embc.2012.6346698

Submit or recommend next manuscript to OALib Journal and we will provide best service for you:

- Publication frequency: Monthly

- 9 subject areas of science, technology and medicine

- Fair and rigorous peer-review system

- Fast publication process

- Article promotion in various social networking sites (LinkedIn, Facebook, Twitter, etc.)

- Maximum dissemination of your research work

Submit Your Paper Online: Click Here to Submit

Or Contact service@oalib.com 